\title{
Leiomiossarcoma retroperitoneal
}

\section{Retroperitoneal Leiomyosarcoma}

Apresenta-se um caso de uma doente de 62 anos, que se apresentou com um quadro de dor abdominal e edemas dos membros inferiores, com 15 dias de evolução. Do estudo realizado, salientam-se a radiografia de tórax (figura 1) e tomografia computorizada (TC) abdominal (figura 2 e 3) e torácica (figura 4). Na radiografia torácica são visíveis múltiplas imagens nodulares, bilaterais, sugestivas de metastização, o que foi confirmado na TC de tórax. Na TC abdominal é visível uma massa sólida com cerca de $22 \times 15 \mathrm{~cm}$, de origem retroperitoneal, sem claro plano de clivagem com a veia cava inferior (figuras 2 y 3 , seta preta). A biopsia da massa abdominal permitiu 0 diagnóstico de leiomiosarcoma retroperitoneal.

Os sarcomas de tecidos moles são neoplasias raras, representando cerca de $0,7 \%$ de todos os tumores malignos ${ }^{1}$. Este grupo de neoplasias apresentam histologias variadas, sendo que 5 a 10\% são leiomiossarcomas e 10 a $20 \%$ tem origem no retroperitoneu. É frequente os leiomiossarcomas terem origem na veia cava inferior. A sua origem retroperitoneal permite serem assintomáticos até serem suficientemente grandes para causarem compressão das estruturas adjacentes $^{2}$. Assim, como foi o caso, manifestam-se frequentemente como massa abdominal, associada a edema uni ou bilateral dos membros inferiores.

Os principais factores de prognóstico são o grau (independente do tipo histológico) e a possibilidade de ressecção cirúrgica completa². A ressecção cirúrgica é o único tratamento potencialmente curati$\mathrm{vo}^{2}$. Devido à complexidade anatómica do retroperitoneu e ao grande tamanho dos tumores a resseção com margens microscopicamente negativas é difícil, sendo as recidivas locoregionais frequentes ${ }^{3} .0$ papel da quimioterapia adjuvante não está bem definido e a radioterapia adjuvante diminui o risco de recorrência, mas não tem impacto na sobrevida. Após cirurgia a sobrevida aos 5 e 10 anos é $51 \%$ e 36\%, respectivamente ${ }^{3}$.

\section{Bibliografía}

1. Hua-Ching Lin, Ming-Teng Chung. Retroperitoneal Leiomyosarcoma: A Case Report and Review of the Literature. J Soc Colon Rectal Surgeon (Taiwan) 2008; 19: 123-7.

2. Mullinax JE, Zager JS, Gonzalez RJ. Current diagnosis and management of retroperitoneal sarcoma. Cancer Control. $2011 \mathrm{Jul} ;$ 18(3): 177-87.

3. Heslin MJ, Lewis JJ, Nadler E, Newman E, Woodruff JM, Casper ES, Leung D, Brennan MF. Prognostic factors associated with long-term survival for retroperitoneal sarcoma: implications for management. Clin Oncol. 1997; 15(8): 2832-9.

\section{Diagnóstico}

\section{Leiomiossarcoma Retroperitoneal}

\section{Mário Pires, Magda Sousa}

Serviço de Medicina Interna. Centro Hospitalar do Baixo Vouga. Aveiro. Portugal

Como citar este artículo: Pires M, Sousa M.

Leiomiossarcoma Retroperitoneal. Galicia Clin 2013; 74 (3): 142

Recibido: 5/3/2013; Aceptado: 9/4/2013
Figura 1. Radiografía de tórax, mostrando metastização pulmonar maciça

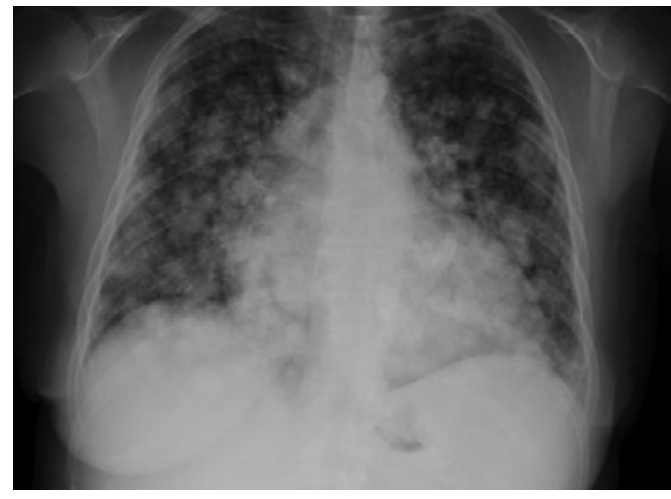

Figura 2. TC abdominal, mostrando massa retroperitoneal de grandes dimensões (veia cava inferior, seta preta).

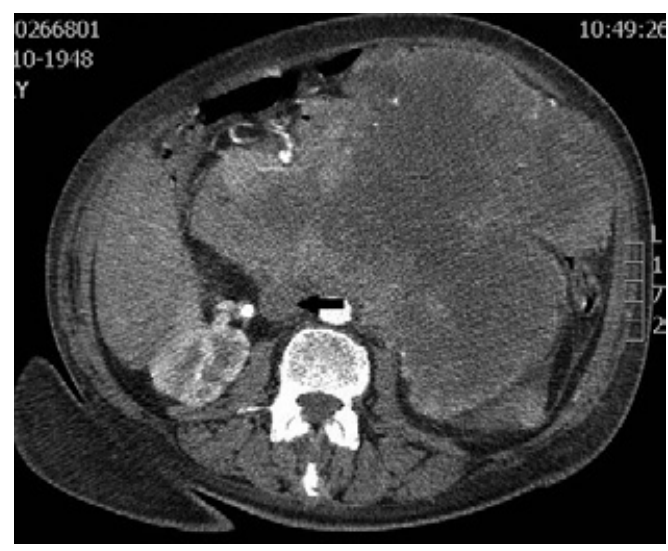

Figura 3. TC abdominal, mostrando massa retroperitoneal de grandes dimensões (veia cava inferior, seta preta).

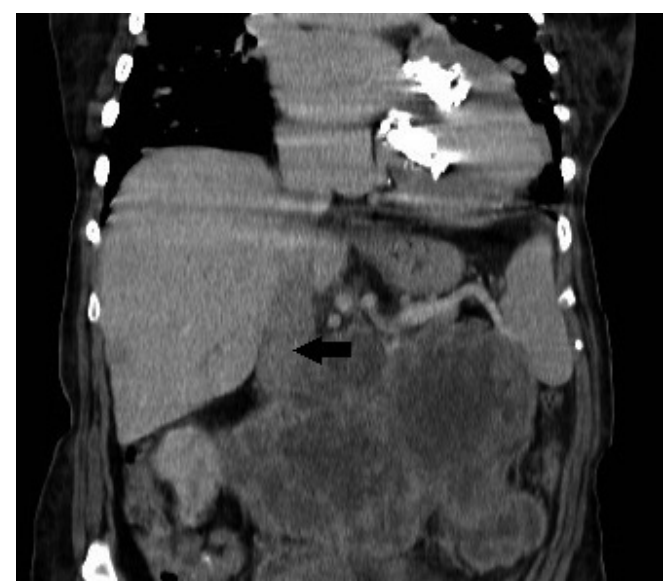

Figura 4. TC toracica, com metastização pulmonar.

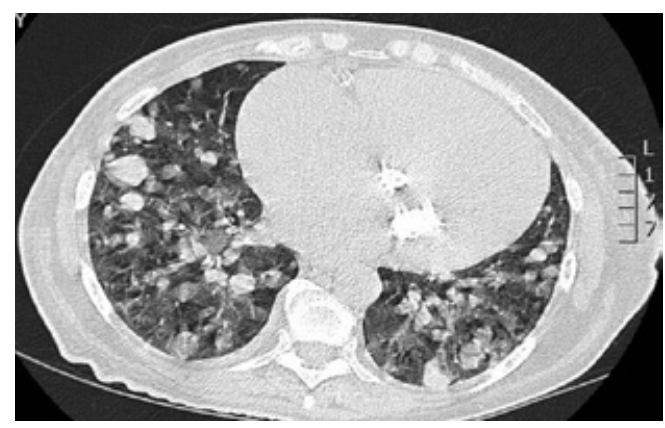

